\title{
O ESTRANHO BATE À PORTA: O INSÓLITO E O MEDO NO CONTO "EPPURE BATTONO ALLA PORTA" DE DINO BUZZATI ${ }^{1}$
}

\author{
Vanessa Matiola (Unesp - FCLAr) \\ Claudia Fernanda de Campos Mauro (Unesp - FCLAr)
}

Recebido em 22 jun 2019. Vanessa Matiola é Licenciada e Bacharel em Aprovado em 29 jul 2019. Letras com habilitação em português/inglês pela Universidade Estadual Paulista Júlio de Mesquita Filho - Faculdade de Ciências e Letras de Araraquara (Unesp - FCLAr). Realizou a graduação com bolsa de estudos pela Fundação Vunesp - Convênio Unesp/Vunesp/SEESP, pesquisando na área de Literatura Italiana. É aluna do programa de Pós-Graduação em Estudos Literários da Unesp - FCLAr e Bolsista pela Coordenação de Aperfeiçoamento de Pessoal de Nível Superior (CAPES), realizando pesquisa na área de Literatura Italiana. Também é aluna de graduação do curso de Letras por reingresso com habilitação em Língua Italiana na Unesp - FCLAr. É Colaboradora voluntária do Projeto Teletandem na mesma instituição.

Claudia Fernanda de Campos Mauro é Doutora em Letras (Teoria Literária e Literatura Comparada) pela USP e Pós-Doutora pela Università degli Studi di Firenze. Atualmente é Professora de graduação e pósgraduação do Departamento de Letras Modernas da

1 Este artigo faz parte da dissertação de mestrado em andamento intitulada "A marca do insólito nos contos de Dino Buzzati". O presente trabalho foi realizado com apoio da Coordenação de Aperfeiçoamento de Pessoal de Nível Superior - Brasil (CAPES) - Código de Financiamento 001. 
Unesp - FCLAr, membro de corpo editorial da Revista de Letras (Unesp, impresso) e membro de corpo editorial da Revista de Letras (Unesp, online). Atua principalmente na área de literatura italiana do século XX. Lattes: http://lattes.cnpq.br/3083005309004357. E-mail: claudia.mauro@unesp.br.

Resumo: As obras literárias do italiano Dino Buzzati são marcadas pela angústia que o autor insere em sua escrita. Seus contos geralmente são estudados como narrativas fantásticas por trazerem um elemento sobrenatural com frequência. Este elemento, por sua vez, é o que faz com que as personagens experimentem uma inquietação angustiante. Contudo, outro possível aspecto que se destaca nas narrativas curtas buzzatianas é o insólito enquanto desencadeador da angústia, uma vez que o insólito é tudo aquilo que foge da realidade de um indivíduo. Ao passar por uma experiência insólita, um sujeito vê todas as suas verdades, componentes que formam a base do seu conceito de "real", desaparecerem. A sua realidade sólida, portanto, se dilui, o que faz com que ele experimente a angústia provocada por algo estranho. Dado que o ensaio "Das Unheimliche" (traduzido como "O estranho" e "O inquietante"), de Sigmund Freud, trata justamente do estranho e é uma das bases fundamentais para o estudo do insólito, este artigo procurará relacionar a teoria freudiana do estranho com o insólito e com o medo dentro do conto "Eppure battono alla porta" ("Contudo, batem à porta"), do escritor italiano Dino Buzzati.

Palavras-chave: Insólito; Estranho; Literatura italiana; Dino Buzzati; Conto.

Abstract: One of the remarkable aspects of Dino Buzzati's literary work is the way the Italian author inserts anguish in his writings. His short stories are usually studied as fantastic narratives because they often bring a supernatural element. This element, 
in its turn, is what makes the characters experience an anguishing inquietude. However, another possible aspect that calls attention in buzzatian short narratives is the uncommon as something that makes anguish appear, as the uncommon is all that escapes from one's reality. When going through an uncommon experience, a person sees all his or her truths, components that form the basis of his concept of 'real', disappear. One's solid reality, therefore, is diluted, which makes this person experience the anguish caused by something strange. Given that the essay 'Das Unheimliche' (translated as 'The uncanny'), by Sigmund Freud, deals precisely with what is strange and that it is one of the fundamental bases for the study of the uncommon, this essay will work as an attempt to associate the Freudian theory of the strange (that is, the uncanny) with the uncommon and the fear in the short story "Eppure battono alla porta" written by Italian writer Dino Buzzati.

Keywords: Uncommon; Uncanny; Italian literature; Dino Buzzati, Short story.

Dino Buzzati foi um escritor italiano do século XX cuja obra mais famosa é o romance $O$ deserto dos Tártaros (1940), devido a um ensaio escrito por Antonio Candido sobre o livro (BERNARDINI, s/d.). Jornalista do Corriere della Sera durante grande parte de sua vida, Buzzati também foi autor de romances, contos, crônicas, poesia, além de ter trabalhado com peças teatrais e musicais. Uma marca de sua obra literária é a angústia que suas personagens experimentam. Alguns temas caros a Buzzati, de acordo com Zangrandi (2014, p.29), eram o sentimento do tempo representado desde a paisagem de ilusão da juventude até a desolação da velhice; o medo da morte; a indiferença do destino; a espera, a dimensão misteriosa do real; a vida quotidiana vista de diversos ângulos, às vezes, ironicamente e, 
outras vezes, de forma angustiante e apocalíptica. No que tange aos contos buzzatianos, é comum a análise dessas narrativas tendo o fantástico como perspectiva, pois o escritor frequentemente utiliza o sobrenatural em seus enredos. Isto fica evidente na coletânea de contos La boutique del mistero, publicado em 1968. O livro em questão reúne contos mais significativos do autor, segundo ele mesmo, e que têm uma atmosfera que se relaciona à ideia que seu título passa: é recheado com histórias misteriosas, que causam um sentimento de estranheza no leitor.

O conto "Eppure battono alla porta" ("Contudo, batem à porta") é um exemplo. Publicado inicialmente em 1942, no volume I sette messaggeri (traduzido em Portugal como Os sete mensageiros), foi inserido nas coletâneas Sessanta racconti e La boutique del mistero, ambas compostas por contos selecionados por Buzzati. "Eppure battono alla porta" mostra a noite dos Gron, que são uma família rica, e alguns de seus amigos. Maria Gron, ao chegar a casa em uma noite de tempestade, se depara com insistentes perguntas de sua filha, Giorgina, acerca de duas estátuas de cachorros da família que ficavam em um parque. A jovem questiona a senhora Gron porque vira uma delas nas margens do rio que fica próximo ao parque sendo levada por um camponês. Stefano Gron, marido de Maria, não se conforma com o ocorrido e tenta compreender como a estátua fora parar lá, enquanto o filho Federico quer saber o que aconteceu com a outra. A senhora Gron evita falar sobre isso e tenta amenizar as preocupações do marido e as interrogações dos demais a todo instante, como se o tema dos cães não tivesse relevância alguma. Todavia, sua tentativa é inútil, pois o assunto sempre retorna: 
Ma sì, ma sì, sono stata io a dire di portarli via e lei così tentava di liquidare la questione «li trovo così antipatici.»

Dal caminetto giunse la voce del padre, una voce profonda e oscillante, forse per la vecchiaia, forse per inquietudine: « Ma come? ma come? Ma perché li hai fatti portar via, cara? Erano due statue antiche, due pezzi di scavo... »" (BUZZATI, 1987, p.54)

Em seguida, barulhos fortes começam a preocupar o senhor Gron, mas Maria sugere que seja apenas uma consequência da chuva forte. Chega, então, o senhor Massigher, que quer advertir a família sobre um possível alagamento no rio que fica próximo ao parque, sendo sempre impedido pela senhora Gron. A narração dá a entender que Maria sabe que alguma coisa está fora do comum, porém, prefere fingir para a família - e talvez até para si mesma - que nada preocupante esteja acontecendo. Massigher tem consciência de tudo isso, pois temos acesso aos pensamentos dele:

'Non ci volete credere, dunque?' pensò con acrimonia [...]. 'Le cose spiacevoli non vi riguardano, vero? Vi pare da zotici il parlarne? II vostro prezioso mondo le ha sempre rifiutate, vero? Voglio vedere, la vostra sdegnosa immunità dove andrà a finire! ${ }^{3}$ (BUZZATI, 1987, p.59).

2 - Mas sim, sim, fui eu quem disse para levá-los embora - e ela tentava, assim, pôr a questão de lado. - Eu os acho tão antipáticos...

Da lareira, veio a voz do pai, uma voz profunda e oscilante, talvez pela velhice, talvez pela inquietude:

- Mas como? Mas como? Mas por que os fez levá-los, querida? Eram duas estátuas antigas, dois pedaços de escavação... (tradução nossa).

3 "Não quer acreditar, então?" pensou com aspereza [...]. "As coisas desagradáveis não lhe preocupam, não é? Lhe parece grosseiro falar sobre elas? O seu precioso mundo sempre as recusou, não é? Quero ver onde irá terminar a sua imunidade desdenhosa!" (tradução dos autores). 
O conto continua com os barulhos altos e frequentes e as coisas não ditas. Mesmo quando surge a sensação de que uma voz oculta esteja reverberando pela mansão, os Gron e os visitantes preferem ignorá-la. Quando uma forma escura começa a se mover no chão do lar dos Gron, Stefano se assusta e chama a atenção de todos. Maria, novamente, dá pouca importância para isso e diz que é apenas a água da chuva que caiu por ali. Todos os presentes resolvem agir como se nada incomum estivesse acontecendo, embora paire uma aura anormal.

Então, um vento forte atinge a casa. Os Gron e suas visitas, percebendo que a água do rio está se aproximando e que faltará iluminação em poucos instantes, se apressam para sair dali o quanto antes. Maria Gron, entretanto, se recusa. Em meio ao desespero das personagens, aterrorizadas com todo o caos que está acontecendo, alguém bate à porta. A narrativa termina com uma fala de Massigher, que dá a entender que a batida foi provocada por alguma força inumana:

"Qualcuno che batte alla porta?» chiese il Martora. "Chi volete che sia?»

"Nessuno» rispose Massigher. «Non cıè nessuno, naturalmente, oramai. Pure battono alla porta, questo è positivo. Un messaggero forse, uno spirito, unıanima, venuta ad avvertire. È una casa di signori, questa. Ci usano dei riguardi, alle volte, quelli dellıaltro mondo.» (BUZZATI, 1987, p.65) ${ }^{4}$

Por seu final aberto, "Eppure battono alla porta" pode ser visto como um exemplo de narrativa fantástica tradicional, que 4 - Alguém que bate à porta? - perguntou Martora. - Quem poderia ser?

- Ninguém - respondeu Massigher. - Naturalmente, não há ninguém agora. Contudo, batem à porta, isto é positivo. Um mensageiro, talvez, um espírito, uma alma que veio para advertir. É uma casa de senhores, esta. Mandam sinais de atenção, às vezes, aqueles do outro mundo. (tradução nossa). 
tem como base as postulações de Tzvetan Todorov em Introdução à literatura fantástica. Esta perspectiva considera que o fantástico puro envolva um elemento que faz com que uma personagem ou o leitor hesite a ponto de se questionar sobre sua natureza sobrenatural ou não. Assim sendo, não ficaria claro se um evento sobrenatural realmente acontecera ou não. No caso do conto apresentado, a hesitação residiria na dúvida de os acontecimentos estranhos terem alguma ligação com o sobrenatural: as estátuas, a chuva intensa, a água que se aproxima, a forma escura que é vista na casa e a voz misteriosa podem estar relacionadas com algo além deste mundo, de acordo com as palavras de Massigher. Contudo, isto parte de uma personagem apenas, e cabe ao leitor acreditar nela ou não. Portanto, o fantástico residiria na dúvida e o conto de Buzzati se encaixa nessa categorização, pois nunca é dito o que de fato está acontecendo nos arredores da mansão dos Gron.

Todavia, certos aspectos de "Eppure battono alla porta" que colaboram para a construção das dúvidas que levam ao fantástico, também permitem uma análise que considere o insólito e, mais especificamente, o estranho que leva ao insólito. É o caso da postura evasiva da mãe da família Gron com relação aos temas das estátuas, dos barulhos e da enchente, por exemplo. Sendo uma categoria mais ampla do que o fantástico, o insólito abre uma visão do conto para além do sobrenatural e, por isso, ainda permite que outros contos de Buzzati sejam trabalhados sob o mesmo viés. O insólito também pode ser entendido como o fator que auxilia na compreensão do porquê da angústia que se faz presente nos contos buzzatianos, podendo ela ser acarretada por algum fator sobrenatural ou não. 
O insólito é definido como aquilo que não é comum: o prefixo "in-" serve como negação de "sólito", isto é, do que é habitual, corriqueiro, frequente. É o que foge do que um indivíduo considera como "realidade" e faz com que entre no âmbito do estranho, do incomum, do anormal, do inusitado, do não usual. Para que algo seja considerado anormal para um sujeito, é necessário que ele tenha consigo uma noção do que é o real e esta noção é construída a partir de verdades. Contudo, cada pessoa traz consigo as suas verdades, o que faz com que elas sejam relativas. Sendo as verdades a base para a construção de uma realidade, e considerando também que elas sejam noções instáveis, a realidade de cada um será também relativa e instável. Em outras palavras, cada indivíduo terá uma noção do real e, então, o que sair do campo de sua compreensão será insólito.

Pessanha (2008) aponta que o prefixo "in-" significa tanto negação quanto imersão, o que levaria a um entendimento do insólito enquanto algo ainda mais plural. A partir desta perspectiva, podemos imaginar que o insólito também seria a imersão no comum, feita de modo que leva um sujeito a enxergar todas as suas singularidades e estranhezas. A realidade passaria a ser vista e apreendida em todas as suas formas, desde a realidade cotidiana até a absurda. Esta mudança de perspectiva, isto é, a troca do conhecimento familiar e confortável pela nova visão das coisas abalaria as verdades de um sujeito e seu entendimento estável acerca do "real", fazendo com que ele tivesse contato com o insólito.

Sobre o insólito ficcional, Batista (2007) escreve:

O insólito [...] é visto não como a simples inserção de elementos da fantasmagoria, mas como força 
que desfaz ou repensa o sólido, tradicionalmente visto como real apreensível, advindo da vivência cotidiana dos leitores reais, em consonância com o senso comum racional. $O$ insólito representarse-ia por um conjunto de elementos da construção da narrativa que marcariam os textos com sua presença enquanto representação de uma concepção diversa do sólido, formando um mundo em que as verdades do universo familiar e previsível dos leitores reais, seres do cotidiano, estariam alteradas. (p.46)

De acordo com García (2007 [2012]), o insólito ficcional aparece em um texto literário através da linguagem, mais especificamente pela maneira como ela é trabalhada em conjunto com as categorias narrativas. Assim sendo, personagem, tempo, espaço e narração aparecerão na narrativa moldados pela forma como o autor resolveu apresentá-los por meio de uma linguagem específica e terão influência na ação que é desenvolvida na história. Uma narrativa que apresente o insólito ficcional terá essas categorias contaminadas de elementos incomuns que fujam do universo familiar do leitor. Ele também escreve que, ainda que apenas uma categoria apresente o elemento insólito de modo mais evidente, as outras categorias serão afetadas por esta, pois há uma relação de interdependência entre elas. Pondo em prática estas colocações, García (2012) analisa a categoria personagem no conto "A gorda indiana" do escritor moçambicano Mia Couto: no conto em questão, a personagem que dá título à narrativa vai emagrecendo gradativamente até desaparecer. O insólito, aqui, aparece principalmente na categoria personagem, dado que sua natureza extraordinária é que dá o toque de anormalidade à narrativa. 
Em "Eppure battono alla porta", pode-se atribuir o motivo da aparição do insólito a todas as categorias, mas principalmente às categorias personagem e narração. Tempo e espaço, por sua vez, aqui considerados como apenas um elemento, seguindo o conceito de cronotopo proposto por Bakhtin (1998) - criam uma sensação angustiante no decorrer do conto. As batidas na porta do lar dos Gron são lembretes do tempo e das horas que passam dentro da casa da família. Cada aviso demonstra que há pouco tempo para o que quer que esteja do lado de fora da casa chegue; dentro da casa, por outro lado, o tempo é lento e a noite passa devagar. Contudo, estes contrastes se dão, em grande parte, devido às personagens: Massigher traz a urgência de sair da casa, enquanto Maria Gron a dissipa.

São ainda essas duas personagens que trazem o insólito ficcional à narrativa, mas não por suas naturezas, como no caso da gorda indiana. No conto de Buzzati, o fato de as duas personagens se contradizerem e esconderem algo constantemente deixa o leitor sem um referencial de verdade. Não se sabe o que está acontecendo e isto dá um caráter estranho à história que está sendo mostrada. Além disso, aquilo que está sendo escondido se impõe mais tarde, também sem explicação evidente. Por fim, sabe-se que há algo sendo escondido somente por causa da narração: é ela que expõe o que Massigher está pensando e os momentos do incômodo de Maria.

Até o momento, temos em consideração que algo insólito é o que sai do que é familiar e, na narrativa, caracteriza-se como algo que sai da realidade do leitor e, por isso, passa a ser visto como estranho. Vê-se, portanto, que é formada uma relação entre o insólito, o familiar, o incomum e o estranho. Ferreira (2009) toca nesses pontos para afirmar que o insólito é o estranho. No capítulo 
"O insólito é o estranho" do livro O insólito e seu duplo (GARCÍA; MOTTA, 2009), a autora decorre sobre o ensaio "Das Unheimliche", de Sigmund Freud, (traduzido como "O inquietante" e "O estranho" em português) para tecer relações entre o Unheimliche, o estranho e o insólito.

Logo no início do texto, Freud aponta que o sentido da palavra "Unheimliche" ("estranho") passa a ideia de algo que gera medo: "Relaciona-se indubitavelmente com o que é assustador - com o que provoca medo e horror; certamente, também, a palavra nem sempre é usada num sentido claramente definível, de modo que tende a coincidir com aquilo que desperta o medo em geral" (FREUD, 1969, p.237). Isto se deve porque o termo "Unheimliche" é associado ao que não é conhecido e familiar, uma vez que o prefixo "un-" nega "Heimliche" ("familiar", "doméstico"). Assim sendo, "Unheimliche" seria o não familiar, não conhecido e, por isso, amedrontador.

Contudo, sua teoria é que nem tudo novo e não conhecido é necessariamente estranho e assustador. Para algo ser estranho, entretanto, é necessário que seja também familiar. Se, por um lado, Heimliche pode ser o que é familiar, relacionado ao que é doméstico, agradável, seguro e confortável, por outro, também pode significar "escondido", "oculto", "privado", o que faz com que se aproxime de Unheimliche, ou seja, de sua negação. É curioso, então, como uma palavra pode conter significados tão variados dentro de si mesma. As várias definições de Heimliche de diferentes dicionários trazidas por Freud mostram como Unheimliche comumente se opõe ao primeiro sentido de Heimliche, isto é, o familiar. Porém, Freud também insere a 
definição de Schelling em seu texto, a qual torna possível apontar um sentido de Unheimliche que se oponha ao segundo significado de Heimliche: Schelling coloca que Unheimliche é tudo o que deveria ter permanecido oculto, mas não o fez.

Isto, então, leva Freud a abordar o que é chamado de "estranho" (Unheimliche). De acordo com ele, o estranho pode aparecer por meio da repetição, como quando alguém vê o mesmo nome ou um mesmo número em um dado período de tempo. Além disso, o estranho também pode ser algo familiar que, em um momento passado, fora reprimido para o inconsciente e que busca retornar. Um exemplo dado é a concepção animista do universo, que acontece quando um indivíduo guarda resquícios da infância e pensa que objetos do mundo podem ter vida quando ele não os está olhando. Também pode acontecer quando alguém acredita que os eventos no mundo possam ser controlados, como a crença em poderes mágicos ou de que algum acontecimento possa ter tido a influência da vontade de uma pessoa ou outro ser. Quando isso acontece, um sentimento de algo estranho nos invade, pois trata-se de uma coisa que não sabemos o que é, mas que, de alguma forma, nos é conhecida.

Tendo isso em mente, é possível notar a presença do estranho e do insólito em "Eppure battono alla porta". O primeiro aspecto a ser levado em conta é a repetição. Durante todo o conto, assuntos são trazidos à conversa dos Gron e há certa insistência em falar sobre eles, como é o caso das estátuas. Mesmo com as tentativas de Maria Gron para encerrar a conversa, o senhor Gron quer compreender o porquê de as estátuas não estarem mais onde estavam: 
« Dimmi, Giorgina » chiese allora la signora Gron, approfittando subito della pausa. « Che libro leggi? È lıultimo romanzo del Massin, quello che mi dicevi? Vorrei leggerlo anchıio quando Iıavrai finito [...]. »

II marito però interruppe: " Giorgina » chiese alla figlia « tu allora che cosa hai fatto? Ti sarai fatta almeno dare il nome! Scusa sai, Maria » aggiunse alludendo all'interruzione. ${ }^{5}$ (BUZZATI, 1987, p.55)

Também é Stefano quem fica abalado com os barulhos que ouve. Na primeira vez, cala-se após a sugestão da senhora Gron sobre serem apenas trovões fortes por causa da chuva. Todavia, na segunda vez, sua perturbação é tamanha que quer assegurar-se que não apenas ele sente que algo está fora do comum:

"Avete sentito? » esclamò il padre, corrugando un pochette la fronte. " Di', Giorgina, hai sentito?...»

«Ho sentito, sì, non capisco » fece la ragazza sbiancatasi in volto.

«Ma è un tuono!» ribatté con prepotenza la madre. «Ma è un tuono qualsiasi... che cosa volete che sia?... Non saranno mica gli spiriti alle volte!»

" II tuono non fa questo rumore, Maria » notò il marito scuotendo la testa." Pareva qui sotto, pareva. " ${ }^{6}$ (BUZZATI, 1987, p.58)

5 - Diga-me, Giorgina - disse, então, a senhora Gron, se aproveitando da pausa. - Que livro você está lendo? É o último romance de Massin, aquele que você me falou? Eu também gostaria de lê-lo quando você terminar [...].

O marido, porém, interrompeu:

- Giorgina - perguntou à filha - e você, o que fez? Deve, ao menos, ter perguntado o nome [do camponês]! Desculpe, Maria - falou, remetendo à interrupção. (tradução nossa).

6 - Vocês escutaram? - exclamou o pai, franzindo a testa. - Diga, Giorgina, você escutou?

- Escutei, sim, não entendo - falou a moça, empalidecendo.

- Mas é um trovão! - rebateu com prepotência a mãe. - Mas é um trovão qualquer... o que queriam que fosse?... Não tem nada de espíritos nas redondezas!

- O trovão não faz esse barulho, Maria - notou o marido, balançando a cabeça. - Parecia que estava aqui embaixo, parecia. (tradução dos autores). 
O que está acontecendo é tão diferente de seu habitual que o senhor Gron começa a se preocupar verdadeiramente. Tudo o que se passa foge tanto do seu entendimento de "normalidade" que ele se pergunta se aquilo está mesmo acontecendo e sua inquietação é tamanha que precisa perguntar à filha se ela também está ouvindo as mesmas coisas que ele. Neste momento, Stefano começa a questionar suas verdades e, portanto, a repensar as bases de sua realidade. Ele não aceita mais uma explicação que se enquadre no que ele considera natural, pois começa a entender que o que está acontecendo não é comum e uma explicação corriqueira não dá conta de abarcar o que realmente esteja se passando. Por isso, Stefano Gron entra no âmbito do insólito.

Há, ainda, outro ponto no qual a repetição aparece e que se dá pela personagem Massigher, que tenta avisar a família Gron sobre o alagamento do rio e sobre a urgência de saberem do estado em que a água está. Em um primeiro momento, tenta falar com todos os presentes, mas Maria conduz a conversa de forma que ele entende que não deve falar sobre o assunto. Instantes depois, tenta conversar diretamente com a senhora Gron, que, desta vez, deixa claro que quer ignorar a questão. Ela não deseja que isso seja discutido de forma alguma, nem com a família toda e nem com ela mesma. Após mais uma insistência de falar sobre a enchente com Maria, Massigher tenta fazer com que Federico saia com ele para ambos verem como está a água do rio e é novamente interrompido por Maria Gron, que não quer que eles saiam no frio.

Se, por um lado, esses temas são repetidamente trazidos à tona, por outro, a matriarca da família Gron os bloqueia sempre que 
emergem. Ela demonstra seu descontentamento e tenta encerrar a conversa tão logo as estátuas, os barulhos e o alagamento são mencionados. Sua técnica mais utilizada é diminuir a proporção que é dada aos assuntos. Entretanto, o leitor sabe que ela tem consciência da importância do que está sendo trazido à tona e quer deixar a conversa de lado para que explicações claras não sejam expostas:

"Mi sono spiegata male " fece la signora accentuando la gentilezza ('che stupida sono stata' pensava intanto 'non potevo trovare qualcosa di meglio?'). "L'avevo detto, sì, di toglierli, ma in termini vaghi, più che altro per scherzo l'avevo detto, naturalmente... ${ }^{7}$ (BUZZATI, 1987, p.54)

Além disso, a narração também mostra que ela quer escapar desses tópicos especificamente porque lhe desagradam. Sua insistência em evitar temas que lhe são indesejáveis sugere que há alguma motivação não dita:

La signora Gron contrasse lievemente il naso; faceva sempre così quando uno toccava argomenti ingrati e bisognava correre ai ripari. La faccenda delle due statue nascondeva qualcosa e lei aveva capito; qualcosa di spiacevole che bisognava quindi tacere. ${ }^{8}$ (BUZZATI, 1987, p.54)

Mais um aspecto apontado por Freud quanto à repetição que leva ao sentimento de Unheimliche é a coincidência. Ele 7 - Me expliquei mal - falou a senhora, acentuando a gentileza ("como fui estúpida" pensava, no entanto, "não consegui encontrar nada de melhor?"). - Eu disse, sim, que poderiam levá-los [os cães], mas em termos vagos, falei mais por brincadeira, naturalmente. (tradução nossa).

8 A senhora Gron contraiu levemente o nariz; fazia sempre assim quando alguém tocava em assuntos indesejáveis e precisava se apressar para repará-los. O caso das duas estátuas escondia alguma coisa e ela tinha entendido; alguma coisa desagradável que tinha que silenciar. (tradução nossa). 
dá exemplos de quando um indivíduo se depara com o mesmo número ou com o mesmo nome: se um número ou um nome fossem vistos uma vez ou outra, não causariam surpresa; contudo, quando alguém se depara com eles com frequência em um pequeno período de tempo, essa coincidência gera estranhamento e a sensação de que haja algum significado por trás do número ou do nome. Em "Eppure battono alla porta", o fato de os barulhos serem escutados na mansão e de o alagamento acontecerem no mesmo dia em que as estátuas foram removidas, unidos à atitude da senhora Gron evitar todos os três assuntos levam a uma sensação estranha. O sincronismo dos acontecimentos leva o leitor a crer que eles estejam ligados de alguma forma que não é explicada.

Ainda no ensaio "O estranho", Freud explica como o princípio animista do mundo também causa o efeito de estranhamento nas pessoas. Como mencionado, esse princípio se liga a um estágio da infância não superado, no qual alguém atribui vida e poderes a objetos inanimados ou que existam forças que controlem os eventos no mundo. No conto, há um momento no qual a possibilidade de as estátuas terem vida é mencionada:

"Trovato giù nel fiume! » commentò ancora il padre, tornando all'argomento dei cani. "Come è possibile che sia finito giù al fiume? Non sarà mica volato, dico.»

«E perché no?» fece il dottor Martora gioviale.

«Perché no cosa, dottore?» chiese la signora Maria, diffidente, non piacendole in genere le facezie del vecchio amico. 
"Dico: e perché è poi escluso che la statua abbia fatto un volo? II fiume passa proprio lì, sotto. Venti metri di salto, dopo tutto. $»^{9}$ (BUZZATI, 1996, p.56)

Mesmo que essa possibilidade seja mencionada por brincadeira, ela incomoda a senhora Gron. Tendo em vista que ela parece saber o motivo pelo qual a noite esteja tão incomum, seu degradado causado pela menção de as estátuas terem vida sugere que este seja outro tópico no qual ela não queira se aprofundar. Em outras palavras, Maria não quis falar sobre os barulhos e a enchentes, mas eram acontecimentos preocupantes; por isso, o fato de os cães desaparecerem e a hipótese de terem vida lhe desagradarem pode ser um indício de que este ponto também seja verdade.

Um ponto que une a repetição e o princípio animista do mundo são as chegadas de pessoas de fora à casa dos Gron a fim de adverti-los. Massigher anuncia sua presença pela campainha, que é escutada pela família. Ele tenta avisá-los sobre a água do rio, mas é impossibilitado por Maria. Depois, o mordomo comunica que o fazendeiro Antonio está ali e pretende falar com algum membro da família. Sua presença é breve, pois também está ali para falar sobre a enchente e não é levado a sério. Quando a água finalmente chega, escuta-se uma batida na porta. Ao questionarem quem poderia ser, Massigher responde: «Non c’è nessuno, naturalmente, oramai. Pure battono alla porta, questo è positivo. Un messaggero forse, uno spirito, um'anima, venuta ad avvertire. È una casa di signori,

9 - Encontrado lá embaixo, no rio! - Comentou ainda o pai, voltando ao assunto dos cães. - Como é possível que tenha ido parar lá? Não terá voado, digo.

- E por que não? - falou o doutor Martora, jovial.

- Por que não o quê, doutor? - perguntou a senhora Maria, desconfiada, não gostando do tipo do gracejo do velho amigo.

- Digo: e por que é exclusa a possibilidade de que a estátua tenha feito um voo? 0 rio passa logo ali abaixo. Seriam vinte metros de salto, afinal. (tradução nossa). 
questa. Ci usano dei riguardi, alle volte, quelli dell'altro mondo. ${ }^{\prime 10}$ (BUZZATI, 1987, p.65). Neste sentido, podemos entender que o que vinha sendo ocultado, sejam as estátuas ou alguma outra coisa desconhecida e inumana, anuncia sua chegada.

Ferreira (2009), ao falar sobre o Unheimliche, escreve que

não há recalque sem retorno do recalcado. A cada retorno, o recalcado esbarra com um soldado vigilante e incansável, chamado eu. Porém, mesmo assim, o inconsciente insiste em romper os bloqueios do eu, o que faz com que o recalcado regresse como disfarce no sintoma [...]. (p.108)

No final do conto, a água, continuamente ignorada pela senhora Gron, vai na direção da casa de forma ameaçadora. Tudo o que fora enterrado com palavras - ou seja, as estátuas, os barulhos e o alagamento - retorna enquanto ação e emerge com potência total. Uma força até então ignorada mostra sua potência, o que nos leva a crer que os temas escondidos eram apenas parte de uma força muito maior, isto é, eram apenas sintomas do retorno do recalcado. Esta força desconhecida, portanto, é o Unheimliche: sendo o que deveria ter permanecido escondido, mas que veio à luz, o estranho é o reprimido que retorna.

Aquilo que fora escondido pela senhora Gron e ignorado por sua família retorna de maneira espantosa. O que vinha sendo ocultado volta com força e, uma vez que retornou com toda sua energia, o reprimido não pode mais ser contido. As postulações de Edmund Burke acerca do sublime, presentes em Sage (1990), mostram que positivo. Um mensageiro, talvez, um espírito, uma alma que veio para advertir. É uma casa de senhores, esta. Mandam sinais de atenção, às vezes, aqueles do outro mundo. (tradução nossa). 
este é provocado por coisas que aterrorizam. Uma das fontes do medo elencadas por Burke é o poder. O que bate à porta da casa dos Gron tem mais poder do que eles e, por isso, amedronta. 0 Unheimliche torna-se incontrolável e apavorante - e, como já colocado por Freud, se relaciona propriamente com o assustador, com o que provoca horror e medo. Zangrandi (2014, p.7) escreve justamente que uma das temáticas de Buzzati é o medo declinado nos seus múltiplos aspectos.

Burke também coloca a obscuridade como outro fator que leva ao sublime. $\mathrm{O}$ medo provocado por algo possivelmente perigoso desaparece assim que conseguimos apreender sua natureza. Desta forma, se não podemos compreender alguma coisa, não somos capazes entender se é potencialmente perigosa ou não e, assim, ela se torna ameaçadora.

O conto de Buzzati é construído inteiramente pela obscuridade e prova disso são os questionamentos repetitivos das personagens. Quando algo estranho acontece, não há uma exposição convincente da natureza do evento que faça com que as personagens retornem à naturalidade. Elas permanecem no campo do insólito e, por isso, as perguntas se repetem. Nem os Gron, nem os visitantes da mansão e nem o leitor recebem, em nenhum momento, alguma explicação sobre os eventos incomuns que acontecem naquela noite. Isso tudo porque as respostas são ocultadas por Maria, o que faz com que permaneçam obscuras.

Ao contrário de muitos contos de Buzzati, "Eppure battono ala porta" não prevê nenhuma verdade pré-estabelecida para que construamos uma realidade clara. Carlos (2011) nota que 
há uma relação entre escrita jornalística e a escrita de ficção de Buzzati, dado que o autor inicia muitos de seus contos e crônicas respondendo aos 5 "W" do inglês: who?, what?, when?, why?, where? (quem?, o quê?, quando?, porque?, onde?). Este modelo de escrita contribui para a criação de verdades, que definirão uma ideia de real. Além disso, é comum que seus contos sejam escritos com narração em primeira pessoa ou em terceira pessoa e com foco em uma personagem. Isso significa que o leitor acompanhará a história pela perspectiva de uma personagem e, portanto, terá acesso à realidade dela. Tudo o que não se enquadrar no que é considerado comum por ela será insólito.

"Eppure battono alla porta" não se enquadra nesta forma de escrita buzzatiana. As respostas quanto a quem fazia o quê, quando, porque e onde não são apresentadas e não acompanhamos as impressões de nenhuma personagem específica. Pelo contrário: além da ausência da perspectiva de alguém, o leitor tem acesso a algumas impressões de Massigher e da senhora Gron, que parecem ser as únicas personagens que sabem um pouco do que está em jogo, mas que, ainda assim, não fornecem informações completas. O desconhecido paira até mesmo quando os pensamentos dessas duas personagens são inseridos na narrativa. O conto se torna incomum, então, por não haver uma realidade definida e o leitor deve construí-la com informações escassas. A história é inteiramente construída a partir da obscuridade, o que leva a uma tensão angustiante, pois há indícios de que algo ameaçador está por vir, mas não se sabe o quê. 


\section{CONSIDERAÇÕES FINAIS}

Podemos notar que o Unheimliche perpassa o conto "Eppure battono alla porta" do escritor italiano Dino Buzzati. As categorias narrativas são o primeiro indício da presença do estranho, tendose no tempo e no espaço elementos provocadores de angústia. Personagens e narração, por sua vez, são as categorias fundamentais que fazem com que o insólito (e, portanto, o estranho) se manifeste no enredo. É a partir da narração que compreendemos que as personagens escondem algo e suas ações são reflexos disso. Além disso, as ações das personagens Massigher e Maria Gron são motivadas justamente por aquilo que escondem.

O estranho aparece ainda na repetição, na coincidência dos eventos da narrativa e na possibilidade de seres inanimados terem vida. Contudo, as respostas são escondidas e os acontecimentos se tornam obscuros. Isto significa que os pontos que levam ao Unheimliche são reprimidos. A tentativa de sepultamento desses elementos, contudo, é vã, pois são apenas sintomas de uma força muito maior que quer se fazer presente. Quando o que estava sendo reprimido retorna com poder e não pode ser controlado, gera medo. As personagens percebem os alertas de que algo incomum está acontecendo, mas, por ser desconhecido, se torna também angustiante. Sua realidade vai sendo diluída aos poucos na narrativa, o que faz com que tenham uma experiência insólita.

\section{REFERÊNCIAS}

BAKHTIN, Mikhail (1998). "Formas de Tempo e Cronotopo no Romance (Ensaios de poética histórica)". In: Questões de literatura e de estética: a teoria do romance. 4.ed. São Paulo: Unesp. 
BATISTA, Angélica Maria Santana (2007). "As (des)fronteiras do insólito na literatura: reflexões e possibilidades na contemporaneidade". In GARCÍA, Flavio (Org.). A banalização do insólito: questões de gênero literário - mecanismos de construção narrativa. Rio de Janeiro: Dialogarts. p.45-65.

BERNARDINI, Aurora (2018). Literatura Fundamental 59 - O deserto dos Tártaros - Aurora Bernardini. Entrevistador: Ederson Granetto. Disponível em: http:// tvcultura.com.br/videos/34237_literatura-fundamental-59-o-deserto-dostartaros-aurora-bernardini.html. Acesso em 12. Set. 2018.

BUZZATI, Dino (1987). “Eppure battono alla porta”. In: La boutique del mistero. Milão: Arnoldo Mondadori Editore.

CARLOS, Ana Maria (2011). "Dino Buzzati jornalista e o insólito no cotidiano". In: Simpósio Internacional De Letras E Linguística, 2. Anais do SILEL. Uberlândia: EDUFU. In http://www.ileel.ufu.br/anaisdosilel/wp-content/uploads/2014/04/ silel2011_1528.pdf Acesso em: 30.Mai. 2017.

FERREIRA, Nadiá Paulo (2009). O insólito e o estranho. In: GARCÍA, Flavio; MOTTA, Marcus Alexandre (Orgs). O insólito e seu duplo. Rio de Janeiro: EdUERJ. p.107-213.

FREUD, Sigmund (1969). "O 'estranho'”. In: . Edição standard brasileira das obras psicológicas completas de Sigmund Freud. Rio de Janeiro: Imago. v.XVII, p.235-269.

GARCÍA, Flavio. "A manifestação do insólito ficcional, na categoria personagem, como marca do fantástico modal: uma leitura de "A gorda indiana", do escritor moçambicano Mia Couto". Revista Eletrônica de Estudos do Discurso e do Corpo, Vitória da Conquista, 2(2), 33-45, jul./dez. 2012a. In http://periodicos.uesb.br/ index.php/redisco/article/viewFile/1254/1145 Acesso em: 08.Ago.2017.

(2007). "O "insólito" na narrativa ficcional: a questão e os conceitos na teoria dos gêneros literários." In: GARCÍA, Flavio (Org.). A banalização do insólito: questões de gênero literário - mecanismos de construção narrativa. Rio de Janeiro: Dialogarts. p.11-22.

PESSANHA, Fábio Santana (2008). O insólito na dimensão do poético: o movimento de um questionar. In: GARCÍA, Flavio (Org.). Narrativas do insólito: passagens e paragens. Rio de Janeiro: Dialogarts. p.32-48. 
SAGE, Victor. Edmund Burke (1757). In: SAGE, Victor (ed.). The Gothick Novel: a selection of critical essays. London: Macmillan. p.33-38.

ZANGRANDI, Silvia (2014). Dino Buzzati: L'uomo, l'artista. Bolonha: Pàtron editore. 